\title{
The Response to Intravenous Glucose Infusion in Normal and Diabetic Subjects*
}

\author{
Ian Burr, William Hudson, Doris Page, and H. Pincus Taft \\ Diabetic and Metabolic Unit, Alfred Hospital, Victoria, Australia \\ Received: November 3, 1969
}

\begin{abstract}
Summary. Data from single injection studies on 23 normal subjects led to development of an intravenous primed - constant infusion test. The plasma glucose response to this test was determined in 48 normal and 24 diabetic subjects. Variation in plasma glucose concentration at equilibrium was minimal in normal and marked in diabetic subjects - assessed by the difference between maximum and minimum glucose concentration over the final $25 \mathrm{~min}$ of a $50 \mathrm{~min}$ infusion. This parameter was used successfully in predicting the course of 16 pregnant women with clinical suspicion of prediabetes unresolved by oral glucose tolerance tests.
\end{abstract}

Réponse à l'infusion intraveineuse de glucose chez les sujets normaux et diabétiques

Résumé. L'étude des résultats obtenus lors d'une injection intraveineuse unique de glucose chez vingt-trois sujets normaux a conduit à la mise au point d'une technique de perfusion constante précédée d'une injection rapide. Ce test a été pratiqué chez 48 sujets normaux et 24 sujets diabétiques. La différence entre les concentrations maximale et minimale du glucose sanguin observées au cours des 25 dernièros minutes du test a été minime chez les sujets normaux, élevée chez les sujets diabétiques. Ce paramètre a permis de prédire l'évolution clini- que de 16 femmes enceintes suspectes de prédiabète non déterminé lors de tests de tolérance au glucose effectués par voie orale.

Die Reaktion auf intravenöse Glucoseinfusion bei normalen und diabetischen Probanden

Zusammenfassung. Die Ergebnisse von Einmalinjektions-Versuchen bei 23 normalen Versuchspersonen führten zur Entwicklung eines aus Stoß- und Dauerinfusion kombinierten Tests. Das Verhalten der Plasma-Glucosespiegel während dieser Belastung wurde bei 48 Stoffwechselgesunden und 24 Diabetikern überprüft. Die Schwankungen der Plasma-Glucosekonzentrationen im Gleichgewichtszustand wurden an Hand der Differenz zwischen maximalen und minimalen Glucosespiegeln während der letzten $25 \mathrm{~min}$ einer $50 \mathrm{~min}$ dauernden Infusionsperiode beurteilt. Sie fielen bei Normalpersonen minimal, bei Diabetikern hingegen deutlich aus. Dieser Parameter konnte erfolgreich zur Voraussage des Verlaufs bei 16 Schwangeren mit klinischem Verdacht auf Prädiabetes herangezogen werden, der durch die orale Glucosebelastung nicht abgeklärt werden konnte.

Key-words: Intravenous glucose infusion, pregnancy, prediabetes.

\section{Introduction}

The present definition of diabetes is essentially a descriptive one, and whilst such terms as "absolute" or "relative" deficiency of insulin are invoked, the diagnosis of diabetes has rested on the ability to demonstrate inappropriately high blood glucose levels. To this end, many intravenous and oral forms of glucose tolerance tests have been utilized in which relatively large glucose loads are administered within a short time interval $[7,10,13,14,16,24]$. This concept of stress has been further extended with the introduction of the cortisone-glucose tolerance test [11]. Although such tests have been of considerable use in the definition of most diabetic states, they often fail to define adequately the presence of early diabetes, particularly in pregnancy [17]. Further, until the advent of insulin immunoassay and the demonstration of "delayed" insulin responses in maturity-onset diabetes $[7,26]$ with the attendant extension of the "quantitative" and "qualitative" insulin deficiency concepts to include a "dynamie" anomaly, the use of such tests has not materially assisted in furthering insight into the aetiology of diabetes.

* Submitted as part fulfillment of the requirements for Doctor of Medicine, Monash University, Melbourne, 1967.
The possibility that significant anomalies of glucose homeostasis may be unmasked by utilization of small glucose loads under conditions of rapidly attained equilibrium has been investigated in this study. The glucose responses obtained following intravenous administration of a small glucose load followed by a constant infusion of glucose have been determined in both normal and diabetic men and women and in pregnant women. Some of these data have previously appeared in abstract form [5].

\section{Methods}

Data from rapid intravenous glucose tolerance tests in twenty-four subjects utilizing doses of 0.118 $0.192 \mathrm{~g} / \mathrm{kg}$, revealed that with loading doses of the order of $0.126 \mathrm{~g} / \mathrm{kg}$ levels of blood glucose $40-60 \mathrm{mg} /$ $100 \mathrm{ml}$ above fasting could be obtained without provoking a rebound fall in glucose levels below the initial fasting value. The rate of glucose disappearance at a level of $40 \mathrm{mg} / 100 \mathrm{ml}$ above fasting, as calculated from these studies, was $273.4 \mathrm{mg} / \mathrm{min}$, S.D. 63.6 (19 subjects).

Glucose load-infusion studies were performed utilizing an initial glucose load of $0.126 \mathrm{~g} / \mathrm{kg}$, administered in $60 \pm 30$ seconds as $50 \%$ glucose, followed immedia- 
tely by a constant glucose infusion of either 250 or $350 \mathrm{mg} / \mathrm{min}$ for 50 minutes. Tests were performed between 8 and 9 a.m. after a 12 hour overnight fast. Blood samples were withdrawn at zero time, one half hour after insertion of a scalp vein needle into an antecubital vein, at 5 minute intervals throughout the infusion, and again 20 minutes after cessation of the test. The patency of the needle was maintained by flushing with saline after each sample withdrawal. The use of tourniquets on the sampling arm was avoided. Dilutional sampling error was reduced by disearding $2 \mathrm{ml}$ prior to blood sampling, $0.1 \mathrm{ml}$ aliquots of each sample were immediately pipetted into $2 \mathrm{ml}$ of distilled water for glucose estimation by the Somogyi and Nelson procedure [22]. Three groups of subjects were investigated.

Group I consisted of 48 normal subjects, of whom 22 were males, 4 were non-pregnant and 22 were pregnant females. All had normal fasting blood glucose levels, none had glycosuria or a elinical or family history of diabetes. All received an initial priming load of $0.126 \mathrm{~g} / \mathrm{kg}$ glucose, 4 were infused at a rate of $350 \mathrm{mg} / \mathrm{minute}$, the remainder were infused at the rate of $250 \mathrm{mg} / \mathrm{min}$. Of these, 4 pregnant and 5 nonpregnant subjects were retested at the higher rate after an interval of two weeks. Those subjects in whom blood glucose levels were not maintained, but fell during infusion at this rate, were retested at a higher rate $(350 \mathrm{mg} / \mathrm{min})$; under these conditions these patients maintained steady blood glucose levels with minimal fluctuation. This type of response was not observed in any of the diabetic subjects tested, and was most often associated with long term ingestion of a high CHO diet. These subjects were not included in the comparative study.

Group II consisted of 13 non-pregnant and 10 pregnant diabetics from the diabetic clinies of the Royal Womens and/or Alfred Hospitals (Melbourne), in whom a definitive diagnosis of diabetes had been previously made on the basis of standard oral glucose tolerance tests. These patients received a priming glucose load of $0.126 \mathrm{~g} / \mathrm{kg}$, followed by an infusion of $250 \mathrm{mg} / \mathrm{min}$. Insulin-dependent patients were studied only if it could be assumed that the effects of insulin administered the day prior to the test would be minimal, and included those who required a single morning dose of NPH insulin or those who used short-acting insulin in the evenings. 'Tests were performed no later than 9 a.m. and insulin was given on completion of the test. Patients controlled on sulphonylureas refrained from taking the agent for one (short-acting) or two (long-acting) days prior to the test. Diet-controlled patients were allowed a free diet for a minimum of three days prior to testing.

Group III consisted of 16 pregnant women who were suspected of having mild or early diabetes. They had glycosuria associated with a positive family history of diabetes, and/or a past obstetrical history which suggested a pre-diabetic state (e.g. previous glycosuria, abnormal but non-diagnostic glucose tolerance tests, apparently affected infants) but in whom on an arbitrary basis defined below, present oral glucose tolerance tests were non-diagnostic or normal. Oral glucose tolerance tests were considered normal if the fasting blood glucose was $110 \mathrm{mg} / 100 \mathrm{ml}$, the peak glucose level $160 \mathrm{mg} / 100 \mathrm{ml}$ and the $21 / 2$ hour level $120 \mathrm{mg} / 100 \mathrm{ml}$; indicative " of diabetes if two or more of these parameters were exceeded; and "possibly" diabetic if one parameter was exceeded and the other two were within $10 \mathrm{mg} / 100 \mathrm{ml}$. Subjects in whom results of oral glucose tolerance tests fitted into these latter two categories were excluded from this study. Patients were prepared as described for those in Group II. All patients were observed closely during and for variable periods after pregnancy (maximum follow-up period to date is two years). Particular atten. tion being paid to complications of pregnancy and changes in oral glucose tolerance during this period. Each baby was examined at birth for the presence of any clinical features commonly seen in infants of diabetic mothers. That is, overweight for age, plethora, visceromegally, tendency to hypoglycaemia and respiratory distress syndrome, rapid water loss in initial neonatal period, general behaviour similar to an infant of lesser gestation.

\section{Results}

In all instances, venous glucose concentrations were plotted against time; the maximum $\left(G_{\max }\right)$, and minimum $\left(G_{\mathrm{min}}\right)$ blood glucose levels recorded during the latter 25 minutes of the infusion and the difference between them were noted.

Normal subjects - Group I: Representative graphs are shown in Fig. 1a and the data summarized in Tables 1 and 2 . In 34 of the 48 subjects, relatively constant blood glucose levels were maintained for the last 25 minutes of glucose infusion at $250 \mathrm{mg} / \mathrm{min}$ (Fig. 1. a). Blood glucose levels fell throughout the infusion in 9 non-pregnant and 5 pregnant subjects. The mean $\left(G_{\max }-G_{\min }\right)$ in the remaining 17 non-pregnant subjects was 8 , SD 4.5 and in the remaining 17 pregnant subjects 8 , SD 4.2 .

Diabetic Subjects - Group II: None showed a fall in blood glucose concentration during the infusion period. The most striking observations were: a) failure to achieve a steady level of blood glucose at any stage of the infusion, as revealed by the marked increase in $\left(G_{\max }-G_{\text {min }}\right)$ ('Table 3 ) Fig. 1 b, and: b) a tendency for much higher blood glucose levels during infusion in diabetic than in normal subjects.

The most significant difference between normal and diabetic subjects was in the degree of fluctuation of blood glucose levels over the final 25 minutes of the infusion, as represented by $\left(G_{\max }-G_{\min }\right)$ Fig. 2 . There was no significant difference between the response of the 17 normal non-pregnant and 17 normal pregnant 
Table 1. Data obtained from intravenous glucose-primed infusion tests in normal subjects (non-pregnant)

\begin{tabular}{llllllr}
\hline Subject & $\begin{array}{l}\text { Age } \\
\text { (yr) }\end{array}$ & $\begin{array}{l}\text { Weight } \\
(\mathrm{kg})\end{array}$ & $\begin{array}{l}\text { Fasting } \\
\text { Blood } \\
\text { Glucose } \\
(\mathrm{mg} / 100 \mathrm{ml})\end{array}$ & $G_{\max }$ & $G_{\min }$ & $G_{\max } G_{\min }$ \\
\hline Bla & 20 & 68.5 & 65 & 133 & 124 & 9 \\
Day & 21 & 64.5 & 64 & 113 & 112 & 1 \\
MiY & 22 & 61.5 & 80 & 140 & 139 & 1 \\
Hab & 22 & 75.0 & 87 & 140 & 138 & 1 \\
Bu & 23 & 60.7 & 74 & 136 & 128 & 8 \\
DU & 20 & 70.7 & 72 & 126 & 116 & 10 \\
Ta & 45 & 77.4 & 84 & 128 & 119 & 9 \\
ToF & 19 & 65.5 & 82 & 154 & 142 & 12 \\
LaJ & 20 & 61.0 & 93 & 160 & 156 & 4 \\
Gre & 29 & 55.0 & 91 & 135 & 128 & 7 \\
Cor & 20 & 78.8 & 75 & 159 & 151 & 8 \\
Mul & 22 & 74.3 & 78 & 158 & 154 & 4 \\
Far & 20 & 76.5 & 75 & 118 & 112 & 6 \\
VaadS & 21 & 78.5 & 73 & 149 & 142 & 7 \\
Qui & 26 & 71.3 & 88 & 147 & 140 & 7 \\
Bro & 45 & 54.0 & 85 & 131 & 126 & 5 \\
Bry & 55 & 54.9 & 70 & 134 & 127 & 7 \\
\hline
\end{tabular}

Table 2. Data obtained from intravenous glucose-primed infusion tests in normal pregnant subjects

\begin{tabular}{|c|c|c|c|c|c|c|c|}
\hline Subject & $\begin{array}{l}\text { Age } \\
\text { (yr) }\end{array}$ & $\begin{array}{l}\text { Weight } \\
(\mathrm{kg})\end{array}$ & $\begin{array}{l}\text { Gestation } \\
\text { (wk) }\end{array}$ & Fasting & $G_{\max }$ & $G_{\min }$ & $G_{\max }-G_{\min }$ \\
\hline Step & 19 & 46.7 & 16 & 71 & 135 & 129 & 6 \\
\hline Wes & 26 & 57.1 & 26 & 67 & 92 & 77 & 15 \\
\hline Fran & 18 & 74.0 & 32 & 61 & 157 & 148 & 9 \\
\hline Bel & 20 & 76.2 & 28 & 66 & 146 & 141 & 5 \\
\hline Deb & 15 & 65.2 & 32 & 55 & 122 & 119 & 3 \\
\hline Les & 18 & 59.2 & 24 & 63 & 117 & 105 & 12 \\
\hline $\mathrm{Nel}$ & 20 & 77.8 & 28 & 82 & 143 & 134 & 9 \\
\hline Meg & 14 & 69.7 & 32 & 65 & 153 & 149 & 4 \\
\hline Wel & 32 & 60.0 & 16 & 71 & 128 & 112 & 16 \\
\hline LeM & 29 & 50.1 & 24 & 54 & 112 & 106 & 6 \\
\hline Lyn & 19 & 19.7 & 28 & 65 & 111 & 96 & 15 \\
\hline Sam & 22 & 80.0 & 16 & 67 & 110 & 105 & 5 \\
\hline Rei & 32 & 55.4 & 12 & 60 & 138 & 132 & 6 \\
\hline Mar & 18 & 50.5 & 16 & 63 & 156 & 144 & 12 \\
\hline Lub & 25 & 55.7 & 16 & 65 & 179 & 175 & 4 \\
\hline Sch & 35 & 61.6 & 32 & 82 & 151 & 142 & 9 \\
\hline Kel & 21 & 83.7 & 34 & 72 & 117 & 106 & 11 \\
\hline
\end{tabular}

Table 3. Data Obtained from intravenous glucose-primed infusion tests in diabetic subjects

\begin{tabular}{|c|c|c|c|c|c|c|c|c|c|c|c|c|}
\hline \multicolumn{6}{|c|}{ A. Diabotic non-pregnant patients } & \multicolumn{7}{|c|}{ B. Diabetic pregnant patients } \\
\hline Subject & $\begin{array}{l}\text { Age } \\
\text { (yr) }\end{array}$ & $\begin{array}{l}\text { Weight } \\
\text { (kg) }\end{array}$ & $G_{\max }$ & $G_{\min }$ & $G_{\max }-G_{\min }$ & Subject & $\begin{array}{l}\text { Age } \\
\text { (yr) }\end{array}$ & $\begin{array}{l}\text { Weight } \\
\text { (kg) }\end{array}$ & $\begin{array}{l}\text { Gestation } \\
\text { (wk) }\end{array}$ & $G_{\max }$ & $G_{\min }$ & $G_{\max }-G_{\min }$ \\
\hline$\overline{\text { Her }}$ & 50 & 64.4 & 131 & 97 & 34 & Rob & 24 & 49.1 & 32 & 189 & 167 & 22 \\
\hline PFL & 52 & 65.9 & 150 & 127 & 23 & Tsa & 27 & 58.5 & 32 & 169 & 146 & 23 \\
\hline Whi & 54 & 73.5 & 154 & 115 & 39 & Con & 21 & 68.5 & 28 & 194 & 165 & 29 \\
\hline BroM & 75 & 45.0 & 222 & 170 & 52 & Nap & 34 & 96.5 & 28 & 226 & 185 & 41 \\
\hline Cat & 48 & 83.0 & 321 & 292 & 29 & Chap & 29 & 70.6 & 8 & 204 & 172 & 32 \\
\hline Han & 67 & 62.2 & 204 & 181 & 23 & Enn & 19 & 55.0 & 28 & 212 & 171 & 41 \\
\hline Goss & 42 & 58.5 & 170 & 140 & 30 & Ort & 23 & 57.0 & 28 & 272 & 213 & 59 \\
\hline Pick & 58 & 75.8 & 255 & 234 & 21 & Ches & 29 & 60.8 & 28 & 210 & 183 & 27 \\
\hline BroR & 19 & 59.7 & 198 & 178 & 20 & Tod & 31 & 61.6 & 32 & 253 & 232 & 21 \\
\hline Sch & 18 & 56.0 & 362 & 333 & 29 & Viv & 25 & 93.8 & 32 & 217 & 198 & 19 \\
\hline Lya & 50 & 80.2 & 317 & 290 & 27 & & & & & & & \\
\hline Ber & 48 & 65.0 & 540 & 437 & 103 & & & & & & & \\
\hline Bay & 52 & 55.2 & 330 & 274 & 56 & & & & & & & \\
\hline
\end{tabular}


Table 4. Summary findings in a group of 16 'pre-diabetic' pregnant patients

\begin{tabular}{|c|c|c|c|c|c|c|c|}
\hline Subject & FHD & Result & $\begin{array}{l}\mathrm{LI} \\
G_{\max }-G_{\min }\end{array}$ & $\begin{array}{l}\text { LI } \\
\text { Result }\end{array}$ & Immediate Complications & Follow-up & $\begin{array}{l}\text { No. months } \\
\text { later }\end{array}$ \\
\hline Bal & - & ND & 4 & $\mathrm{~N}$ & - & $\mathrm{N} O G T$ & 12 \\
\hline LJu & + & ND & 4 & $\mathrm{~N}$ & - & $\begin{array}{l}\text { No clinical evidence } \\
\text { diabetes; OGT refused }\end{array}$ & \\
\hline Bla & + & ND & 7 & $\mathrm{~N}$ & $\begin{array}{l}\text { Caesarean section; } \\
\text { cephalopelvic } \\
\text { disproportion }\end{array}$ & N OGT & 16 \\
\hline Ste & + & $\mathrm{ND}$ & $\downarrow$ & $\mathrm{N}$ & - & N OGT & 12 \\
\hline BroN & + & ND & $\downarrow$ & $\mathrm{N}$ & - & N OGT & 9 \\
\hline Sch & + & ND & 9 & $\mathrm{~N}$ & - & $\mathrm{NOGT}$ & 6 \\
\hline Mob & - & ND & 13 & $\mathrm{~N}$ & - & N OGT; abn LI & 12 \\
\hline Lum & - & $\mathrm{N}$ & 17 & $\mathrm{~N}$ & Abortion 2nd trimester & N OGT; N LI & 12 \\
\hline Mor & - & $1 \mathrm{~N} ; 1 \mathrm{ND}$ & 33 & $\mathrm{D}$ & Affected infant & - & \\
\hline Jack & + & $\mathrm{N}$ & 20 & $\mathrm{D}$ & - & Diabetic OGT & 12 \\
\hline RobY & - & $\mathrm{N}$ & 22 & $\mathrm{D}$ & Affected infant & Diabetic OGT & 6 \\
\hline GO & - & $1 \mathrm{~N} ; 1 \mathrm{ND}$ & 28 & $\mathrm{D}$ & Affected infant-diet & LI diabetic & 5 \\
\hline Ted & + & ND & 22 & $\mathrm{D}$ & - & $\mathrm{N}$ OGT & 12 \\
\hline Hig & - & $1 \mathrm{~N} ; 1 \mathrm{D}^{\mathrm{a}}$ & 26 & $\mathrm{D}$ & $\begin{array}{l}\text { Treated with tolbutamide } \\
\text { latter part pregnancy }\end{array}$ & & \\
\hline Rat & + & $2 \mathrm{ND} ; 2 \mathrm{~N}$ & 28 & $\mathrm{D}$ & Affected infant & D OGT & 12 \\
\hline Dys & + & ND & 19 & $D$ & Affected infant & ND OGT & 14 \\
\hline
\end{tabular}

$\mathrm{N}=$ Normal $\quad$ FHD $=$ Family history diabetes $\quad$ LI = Load-infusion intravenous glucose test $\mathrm{ND}=$ Non-diagnostic $\quad$ OGT $=$ Oral glucose tolerance test $(50 \mathrm{~g}$ load $)$.

a OGT diagnostic of diabetes $3 \frac{1 / 2}{2}$ mo after abnormality detected by LI method.

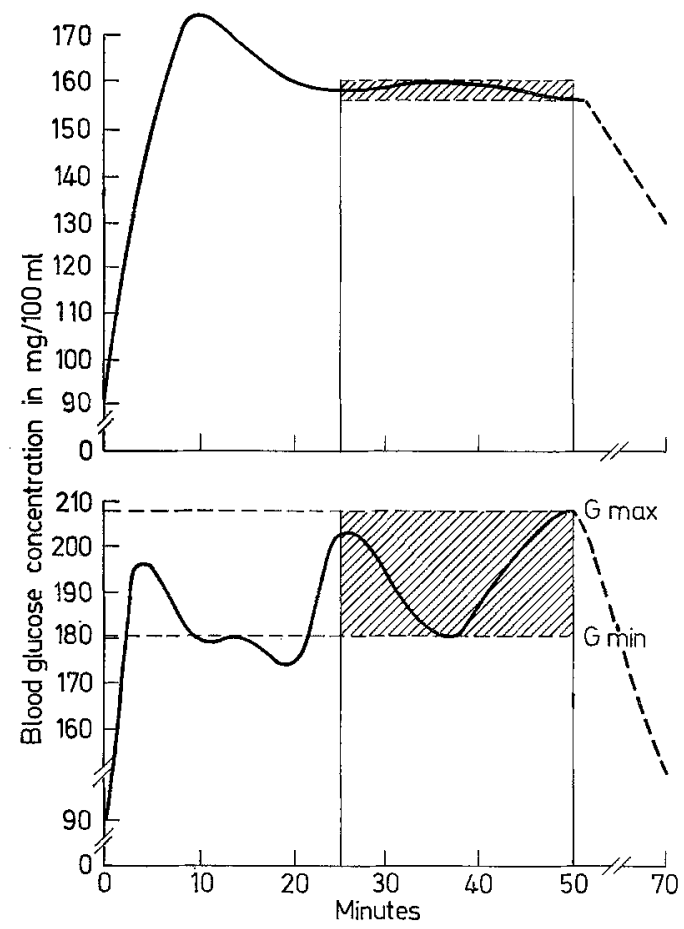

Fig. 1. Sample graphs of glucose concentrations during and after IV glucose-primed infusion

a) Normal subject (JLa), infusion rate $250 \mathrm{mg} / \mathrm{min}$

b) Diabetic patient (Cher), infusion rate $250 \mathrm{mg} / \mathrm{min}$

subjects in whom blood glucose levels were maintained during infusion of $250 \mathrm{mg} / \mathrm{min}$, nor between the $10 \mathrm{preg}$ nant and 13 non-pregnant diabetics. There was a statistically significant difference between the normal and the diabetic, the mean $\left(G_{\max }-G_{\min }\right)$ in the diabetic

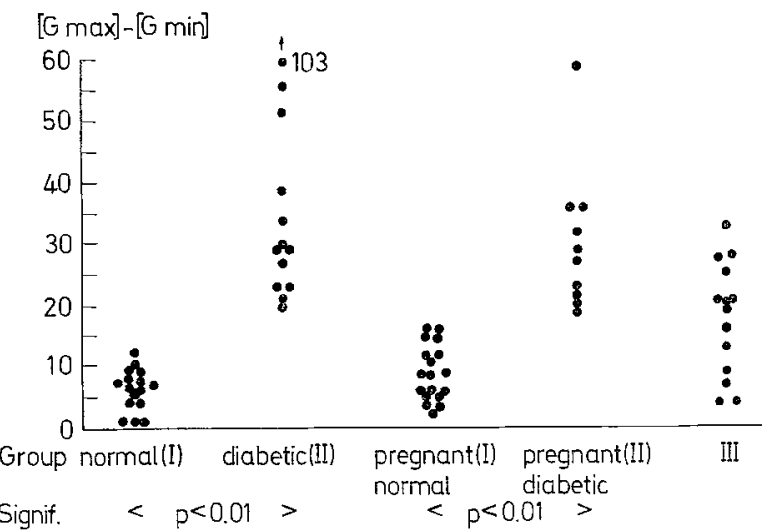

Fig. 2. $\left(G_{\max }\right)-\left(G_{\min }\right)$ values in normal (Group I) and diabetic subjects (Group II) as obtained from glucose infusion data

being significantly greater; $p<0.01^{*}$, this difference was maintained in the pregnant groups, $p<0.01^{*}$. Assuming a normal physiological range of mean $\pm 2 \mathrm{SD}$ where only the upper limit is significant, the upper limit of $\left(G_{\max }-G_{\min }\right)$ was 17 in both normal non-pregnant and normal pregnant patients.

Results in Group III: These are summarized in Table 4 . These 16 pregnant women were classified into 'normal' or 'diabetic' according to the result of the glucose load-infusion test. Normal results were observed in 8 patients, 6 of whom failed to develop any clinical or biochemical evidence of diabetes during the period of follow-up (as determined by oral glucose tolerance tests) and none of their infants showed any of the signs sometimes observed in the presence of maternal dia-

* Wilcoxon rank test. 
betes. In one, the pregnancy was uneventful and the infant was normal; the result of a follow-up glucose load infusion test 14 months later was in the diabetic range, an oral glucose tolerance test at this time was abnormal but not diagnostic of diabetes. The eighth patient showed no evidence of diabetes during pregnancy and delivered a normal infant. Follow-up oral glucose tolerance tests could not be performed.

Of the 8 patients considered to be diabetic from the results of glucose load-infusion tests, 5 had infants with clinical features associated with maternal diabetes $[3,6,8,9,12,19,25,27]$. (1 infant died in the neonatal period). Of these, 3 subsequently had $[6,11$ and 12 months postpartum] results of oral glucose tolerance tests which indicated diabetes. The remaining patients delivered apparently normal infants. One has shown no further evidence of diabetes; in one an oral glucose tolerance test 14 months postpartum was diagnostic of diabetes; and in the third, a similar response was obtained during the pregnancy, 2 months after the abnormality had been demonstrated by the load-infusion technique. This last patient received tolbutamide for the remainder of her pregnancy.

In summary, none of those patients considered to be normal from the results of the intravenous glucoseload infusion test have had subsequent evidence of diabetes. Seven of the eight considered to be diabetic by this test have shown further evidence of diabetes.

\section{Discussion}

An intravenous glucose primed-infusion technique has been described in which the recorded glucose responses have enabled ready differentiation between normal and diabetic subjects. The doses of glucose used in these studies were low in comparison with more conventional forms of testing. The priming load was insufficient to produce a rebound fall in blood glucose levels below the fasting value, and the infusion rate was lower than that which Hlad [16] had demonstrated would not produce marked disturbance of glucose regulatory mechanisms. Further, the rate of glucose absorption following conventional oral loads is approximately $40 \mathrm{~g}$ per hour $[20,23]$, that is double the rate of infusion used in this study. These considerations indicate that this glucose primed-infusion method produces a lower stimulus to pancreatic insulin secretion than do standard oral or intravenous methods, and suggests that the abnormality in glucose utilization demonstrated by this test in maturity-onset diabetes, may not be dependent upon a simple quantitative reduction in the capacity of the pancreas to secrete insulin.

The responses obtained in this study, marked fluctuation in glucose concentrations in diabetic states with relatively constant levels in normal subjects, are similar to those previously described in the fasting state $[1,2]$ and with recent studies illustrating marked variation in blood glucose levels in diabetics over a 24 hour period [18]. The pattern of such changes suggests the presence of a "dampening" mechanism in normal subjects, which prevents wide fluctuations in blood glucose levels under primed-infusion conditions, and implies the existence of a co-ordinating system controlling the phasic relationship between the activity of factors which raise and lower blood glucose levels. This concept implies that the activity of factors which would tend to increase blood glucose levels and the activity of factors tending to lower blood glucose levels are of approximately equal potential power and that both are operating continuously. The net effect on blood glucose concentrations at any one time would depend on the relative activities of these opposing systems, and therefore the phase difference between them. In this event, if the activities of both systems were completely out of phase, such that one system was minimally active at the same time as the other was maximally active, the effects on blood sugar would be additive and gross fluctuations in blood glucose concentrations would be anticipated. When however, these activities were for example $45^{\circ}$ out of phase then "dampening" of blood glucose fluctuations would be expected to occur. This latter condition would require that when blood glucose levels are falling, mechanisms for increasing the blood glucose level be activated before the nadir is reached, and conversely that as blood glucose rises mechanisms for lowering same would be activated prior to the attainment of the peak. Thus, for steady state conditions to occur precise control over the timing of activation of the two systems would appear necessary, particularly when the system is disturbed, e.g. in feeding-fasting cycles. It seems unlikely that such control would be attained through random operation of uncoördinated events. It has been suggested, that in the post prandial state the normal fluctuations in blood glucose level may be due to interaction between glucagon and insulin [2], and that these changes are dependent on the liver $[1,4]$.

The possibility that control over timing of activation of factors influencing blood glucose levels is exerted by the central nervous system and mediated by the autonomic nervous system, is considered in the accompanying paper, [28].

Preliminary studies utilizing the glucose-primedinfusion method in selected pregnant patients suggest that the anomaly demonstrated in diabetic patients may be manifest early in the development of the clinical disorder.

Acknowledgement: The financial assistance of Burroughs Wellcome and Co. Australia and the Alfred Hospital Research Committee; and the statistical help provided by Mr. J.A. Burr, Department of Mathematics, Melbourne and Swinbourne Technical Colleges, the cooperation of the Staff of the Royal Womens and Alfred Hospitals are gratefully acknowledged. 


\section{References}

1. Anderson, G.E., Hillman, R.W., Van Elk, I.F.A., Perfetto, A.J.: Post absorptive undulations and oscillations in blood glucose. Amer. J. clin. Nutr. 4, $673(1956)$.

2. -Monaco, R.N., Perfetto, A.J., Termine, C.M.: A Physiologic role for glucagon. Diabetes 6, 239-247 (1967).

3. Berglund, G., Zetterström, R.: Infants of diabetic mothers. Foetal hypoxia in maternal diabetes. Acta paediat. Scand. 43, 368-373 (1954).

4. Bondy, P.K.: Spontaneous fluctuations in glucose content of hepatic venous blood in resting normal human beings. J. clin. Invest. 31, 231-236 (1952).

5. Burr, I.M.: Central Nervous System Control over Glucose Homeostasis. Proc. 59th Annual Meeting, Amer. Soc. for Clin. Investigation, pp. 21-22, 1967 .

6. Cardell, B.S.: The infants of diabetic mothers. A morphological study. J. Obstet. Gynaec. Brit. Emp. 60, 834-853 (1953).

7. Cerasi, E., Luft, R.: Plasma Insulin response to sustained hyperglycaemia induced by glucose infusion in human subjects. Lancet 1963 II, $1359-1361$.

8. Cheek, D.B., Maddison, T.C., Malinek, M., Coldbeck, J.H.: Further observations on the corrected bromide space of the neonate and investigation of water and electrolyte status in infants. Pediatrics 28, 861-869 (1961).

9. Clapp, W.M., Butterfield, J.L., O'Brien, D.: Body water compartments in the premature infant, with special reference to the effects of the respiratory distress syndrome and of maternal diabetes and toxemia. Pediatries 29, $883-889$ (1962).

10. Dyck, D.R., Moorhouse, J.A.: A high-dose intravenous glucose tolerance test. J, clin. Endocr. 26, 1032-1038 (1966).

11. Fajans, S.S., Conn, J.W.: An approach to the prediction of diabetes mellitus by modification of the glucose tolerance test with cortisone. Diabetes $\mathbf{3}$, 296 - 304 (1954).

12. Fee, B., Weil, W.B.: Body composition of a diabetic offspring by direct analysis. Amer. J. Dis. Child. 100, $718-719(1960)$

13. Franckson, J.R.M., Ooms, H.A., Bellens, R., Conard, V., Bastenic, P.A.: Physiologic significance of the intravenous glucose tolerance test. Metabolism. 11, $482-500(1962)$.

14. Grimaldi, R.D.: Comparison of oral and intravenous glucose tolerance tests during pregnancy. Diabetes 18, $357-358$ (1969)
15. Himsworth, H.P.: High carbohydrate diets and insulin efficiency. Brit. med. J. 1934 II, $57-60$.

16. Hlad, C.J., Elrick, H.: Kinetics of glucose utilization: New method of data analysis. J. clin. Endocr. 19, $1258-1273(1959)$.

17. Jackson, W.P.U.: Prediabetes. A synthesis. Postgrad. med. J. 35, 287-296 (1959).

18. Kachko, D.M., Kie, T.H., Cunningham, E.J., Durns, T.W.: Glucose homeostasis in normal and diabetic subjects. Diabetes 18, 362-365 (1969).

19. Komrower, G.M.: Blood sugar levels in babies born of diabetic mothers. Arch. Dis. Child. 29, 28-33 (1954).

20. Langner, P.H., Romansky, M.J., Robin, E.D.: Fallacy of Exton-Rose glueose tolerance test. Amer. J. med. Sc. 212, 466-470 (1946).

21. McKean, R.M., Myers, G.B., Von der Heide, E.E.: Blood glucose clearance; its determination by microinterval method; studies in normal and diabetic persons. Amer. J. med. Sc. 189, 702-714 (1934).

22. Nelson, N.: Photometric adaption of Somogyi method for determination of glucose. J. biol. Chem. 153, 375380 (1944).

23. Warren, R., Karr, W.H., Hoffman, O.D., Abbott, W.O.: Intubation studies of human small intestine; absorption expulsion of glucose from stomach. Amer. J. med. Sc. 200, 639-648 (1940).

24. Wilkerson, H. L., Remein, Q. R.: Studies of abnormal carbohydrate metabolism in pregnancy. The significance of impaired glucose tolerance. Diabetes 6, 324329 (1957).

25. Woolf, N., Jackson, W.P.U.: Maternal prediabetes and the foetal pancreas. J. Path. Bact. 74, 223-226 (1957).

26. Yalow, B.S., Berson, S.A.: Plasma insulin concentrations in nondiabetic and early diabetic subjects. Diabetes 9, 254-261 (1960).

27. Zetterström, R., Arnhold, R.G.: Impaired calciumphosphate homeostasis in newborn infants of diabetic mothers. Acta paediat. Scand. 47, $107-112$ (1958).

28. Burr, I.M., Hudson, W., Page, D., and Taft, H.P.: Observations on the effect of a ganglion blocking agent on responses to intravenous glucose infusion. Diabetologia $6,467-472(1970)$.

\section{Dr. I. Burr}

Institut de Biochimie Clinique

Sentier de la Roseraie

CH-1211 Genève 4 